\title{
EDITORIAL
}

\section{La interacción educación-investigación-innovación en ingeniería}

E INNOVACION

EN INGENERIAS

ISSN2344-8652

\section{Jorge Abraham Díaz Rodríguez}

Universidad Nacional Autónoma de México (UNAM), México

En un mundo globalizado el conocimiento y el avance de la tecnología juegan un papel estratégico en el crecimiento económico y social de un país, tienen como factores principales la transferencia del saber y la producción.

Las universidades para definir su misión y cumplirla, deben considerar el mundo social dinámico y cambiante en el que se encuentran. Las universidades tienen un papel moral como formadoras de una sociedad crítica, que proponga un futuro prominente. Por tanto, corresponde a las universidades ejercer la tarea educativa como instrumento de comunicación avanzada y de progreso social; como tal, sus funciones básicas son la educación, la investigación y la transmisión del conocimiento.

La investigación es la actividad con la que la Universidad cumple una función muy importante, también representa un papel axial en la propia Universidad; la libertad académica, la autocrítica, la interacción de grupos que se estimulan unos a otros perpetuando y transmitiendo diversas disciplinas, así como, el rigor requerido por las funciones educativas hacen de la Universidad el sitio ideal para llevar a cabo la investigación.

Sin duda, el desarrollo científico, tecnológico y de innovación son pilares fundamentales para el progreso económico, social y sostenible de un país. Para apoyar esta afirmación, conviene mencionar el caso de la República de Corea, más conocida como Corea del Sur, que ha logrado niveles de crecimiento y bienestar social en una generación, gracias al estímulo económico a la Ciencia, la Tecnología y la Innovación (CTI). Corea del Sur en 1960, era un típico país en desarrollo, con un mercado doméstico pequeño, con una economía básicamente agraria. A partir de esa situación la Asamblea Nacional Coreana decide apoyar decididamente la CTI para realizar una transformación sin precedentes hasta convertirla, a nivel mundial, en una de las economías más dinámicas y prosperas de la actualidad. Conviene resaltar que el enorme progreso de Corea del Sur se debió a la decidida y generosa inversión en Investigación y Desarrollo (lyD) que mejoró productos, procesos y servicios para su comercialización. Las líneas de acción fueron las políticas públicas destinadas a impulsar la educación y la formación de personal especializado, el aumento del PIB en el rublo de CyT, así como un aumento de la participación del sector privado en actividades de lyD, además, en la creación de empresas de base tecnológica.

Según coinciden la mayoría de los científicos, la sociedad del conocimiento, el actual paradigma, en la próxima década veremos más desarrollos tecnológicos que en los últimos 50 años, el motivo es que la ciencia y la tecnología están creciendo en forma exponencial. 
La ingeniería es un pilar en el desarrollo de la sociedad moderna, por tanto, las facultades o escuelas de ingeniería tienen como misión la formación de los ingenieros, con un conjunto de conocimientos científicos y tecnológicos para la innovación, invención, desarrollo y mejora de técnicas y herramientas para satisfacer las necesidades de la sociedad moderna.

Así que conviene reflexionar en la necesidad de convencer a la sociedad y al gobierno de invertir más recursos económicos en $\mathrm{CTI}$, con una visión compartida entre el gobierno, la academia, la industria y la ciudadanía. 